\title{
Holistic approach of the curriculum of Greek junior high school on lithosphere and the implementation of the GeoCause - PaP - CoRe baseline approach on geoscience curriculum development.
}

\author{
Bakopoulou A. ${ }^{1}$, Antonarakou A. ${ }^{1}$, Lozios S. ${ }^{1}$, Zambetakis - Lekkas A. ${ }^{1}$ \\ ${ }^{1}$ National and Kapodistrian University of Athens, Faculty of Geology and Geoenvironment, \\ Panepistimiopolis, Zografou, Athens, Greece
}

\begin{abstract}
This paper examines the effectiveness and the thoroughness of the Greek curriculum on lithosphere of 1st class of junior high school. It discusses the curriculum and textbook ambiguities that lead to conceptual and cognitional gap. We list the criteria (new, revised, existing) for the development of geoscience curriculum. We propose a revised lithosphere curriculum mainly based on a new approach named GeoCause - PaP $\mathrm{CoRe}$, which considers Earth as a giant geosystem and emphasizes on the cause, parameters, processes and result of the phenomenon. During the pilot implementation of the experimental lithosphere curriculum, we used the $\mathrm{GCl}$ tool in order to enhance and revise it. The preliminary results of the research showed that students constructed a robust cognitive framework which consequently led to conceptual change. This approach can become the baseline for the construction of all geoscience curricula and the teaching and learning techniques. The $\mathrm{GCl}$ tool can offer continuous feedback and revise of geoscience curricula in general.
\end{abstract}

Key words: curriculum, lithosphere, geosystem, geotool, geosystem thinking

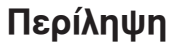

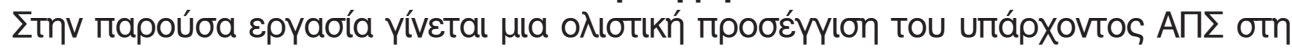

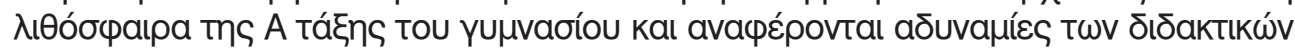

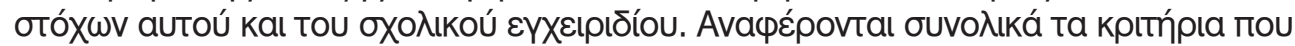

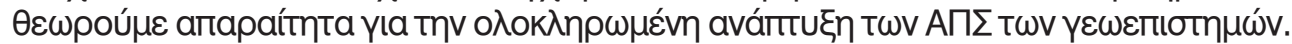

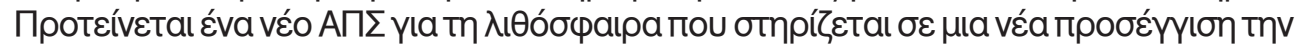

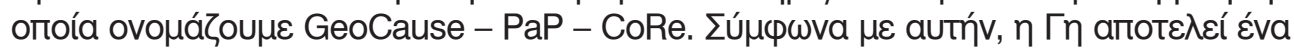

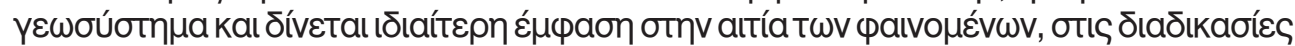

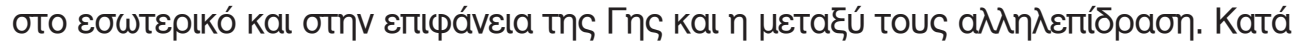

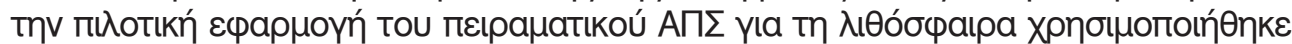

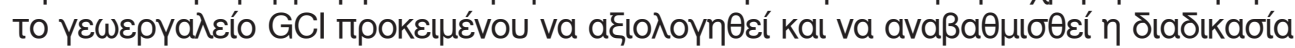

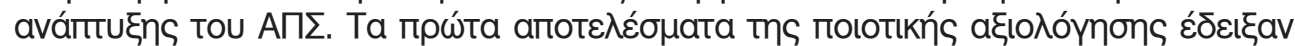

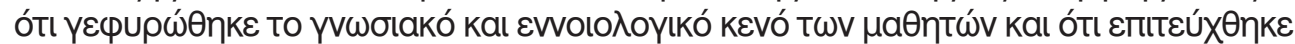

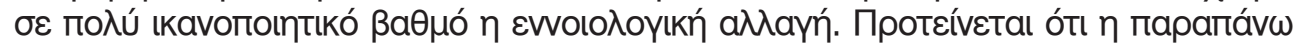

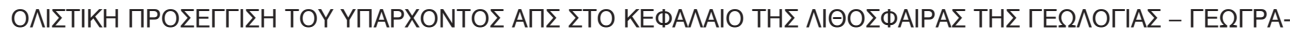

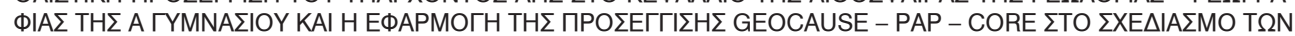
$A \Pi \Sigma T \Omega N \Gamma E \Omega E \Pi I \Sigma T H M \Omega N$. 


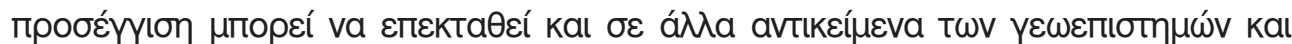

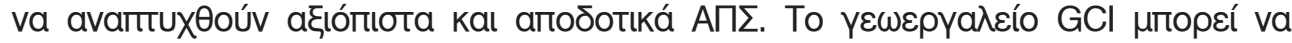

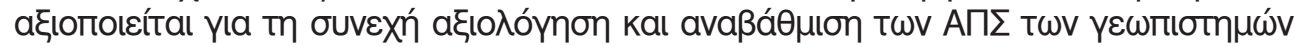

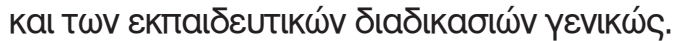

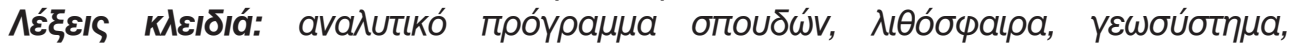

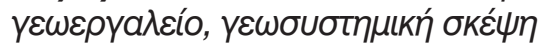

\section{Purpose - Introduction}

The paper is meant to inform the curriculum process by drawing attention on important aspects of current education and curriculum quality that underpin options considered in the process of developing the New Geoscience Curricula Framework.

It also examines the effectiveness and the thoroughness of the Greek curriculum on lithosphere of 1st class of junior high school, underlines the drawbacks, revises and proposes new objectives. It revises and unifies the criteria referred in literature and proposes new ones for the construction of a geoscience curriculum. It also proposes a new reconstructed lithosphere curriculum which is based on a new baseline approach called GeoCause - PaP - CoRe. The latter is continuously upgraded through the $\mathrm{GCl}$ tool. This research for lithosphere focuses on the geodynamic processes, their interaction and their expression from the inner part of Earth to the surface. Processes such as erosion, corrosion are not studied herein. The holistic approach refers to whether the curriculum examines geodynamic events thoroughly and correlatively within the wider system of Earth and not separately as autonomous units.

Merrits et al (1998) argue that Earth is a complex group of interacting systems, so scientists study it from a new perspective called system thinking. Earth system science focuses on the interactions among different Earth systems and the changes that occur in them with time. Earth system science views the whole Earth as a single system in which matter and energy are cycled through numerous subsystems. Earth is a dynamic system in which energy causes the condition or state of the system to change with time.

A critical aspect of Earth System Science (ESS) literacy is the ability to apply "systems thinking", which can be defined as "a framework for seeing interrelationships rather than things, for seeing patterns of change rather than static snapshots" (Senge, 1990, p. 69). Mayer $(1993,1999)$ emphasizes that there is a need for school science programs that more effectively develop knowledge of Earth systems. And there is a need for secondary school science curricula that develop such knowledge. Because students are both future science leaders that will encounter Earth problems and the educated citizenry who would be enabled to encourage and adopt solutions to Earth and environment problems. What all of the attempts to integrate the science curriculum in the past have lacked was a conceptual focus.

The reasoning processes used in system science are largely absent from science curricula (Mayer 1999), though Eger (1972, 1973) argues for the inclusion of hermeneutics in science curricula generally. Frodeman (1995) considers hermeneutics a central component of system science reasoning.

Kuhn et al (2008) also emphasize the 
importance of scientific thinking and propose ways to achieve skilled scientific thinking, a prerequisite for students to succeed conceptual change. Clark et al (2009) developed the Cause-MaP method to expose students to systems thinking, encourage reasoning about transformations that occur in Earth systems, and to recognize the importance of the causes driving transformative processes that generate Earth change through time.

Greek lithosphere curriculum at 1st class of junior high school focuses on separate terms and separate procedures. Existing curriculum fails to correlate processes between them, or study the cause and the result of the processes in the interior and at the surface of Earth. Thus, it omits the study of Earth as a giant geosystem. Therefore, it is not only the lack of conceptual focus but also the absence of cognitional interaction and thoroughness. Therefore, a reconstruction on Greek lithosphere curriculum at junior high school is deemed necessary. Leontakianakos et al (2013) support that a) the term "lithosphere" is not covered adequately as described in the textbook of the 1st grade of junior high-school, b) The majority of the didactic objectives settled by the Curriculum of the Ministry of Education were only partially achieved. The same authors also recommend that the disciplinary approach towards curriculum objectives has to be revised and improved in terms of Earth geosystem approach, system and scientific thinking. After the restructuring of objectives curriculum, the term "lithosphere" would be much easier to be effectively and thoroughly developed according to the existing and future societal and environmental needs.

\section{Comments in the objectives for the existing lithosphere culliculum}

The initiative for this research stems from (a) queries of non-geologist teacher colleagues, who are 'assigned' to teach geology - geography in 1st class of Greek junior high school. These colleagues were bewildered by the ambiguity of some objectives of the existing curriculum on lithosphere, (b) the persistent cognitional - conceptual gap of students on lithosphere. Based on the aforementioned, on literature and on personal teaching experience, some comments on the objectives for the existing lithosphere curriculum are pointed out:

1. The main impediment of this curriculum is that ignores the study of Earth as a geosystem. Consequently system thinking is underdeveloped, interactions and correlations among events are merely developed and therefore raise obstacles in the construction of effective objectives.

2. The correlation among the geodynamic processes and between processes and their surficial expression is unequally developed.

3. The initial cause of all the processes happening in the interior and at the surface of Earth is absent.

4. The first objective "To define the main parts of Earth structure" should be taught at the "Lithosphere" chapter (plate movements, earthquakes, volcanoes, mountains), following the structure of the textbook and not together with the "Earth movements in space" as indicated in the curriculum.

5. The fourth objective "To distinguish the dynamics of geologic parameters ........" could be rephrased to "To distinguish the dynamics of geo- 
logic/geodynamic processes ........". Because it is the processes that can be characterized as dynamic in the interior and at the surface of Earth. This dynamics is though attributed to parameters such as temperature.

6. The fourth and fifth objectives refer to "endogenic forces" and "geologic forces" which are ambiguous terms and should be specified what they refer to.

7. The fourth and the fifth objectives cannot be achieved because the description of the geodynamic processes in the interior of Earth is inadequate. So students can neither correlate processes (because they are not taught), nor can they realize the dynamics of Earth and the ceaseless change of Earth relief.

Finally, the terminology used in this curriculum (geologic forces, endogenic forces) should be avoided since it is inconsistent with the scientific method and can raise ambiguities and misunderstandings. The lack of ideas such as Earth system, system and scientific thinking, and especially the lack of cause of the phenomenon and the correlation among the processes of the phenomenon create cognitive gap which subsequently leads to conceptual gap of students.

\section{Comments on the existing school textbookon lithosphere}

It is consequent that the aforementioned ambiguities and the lack of an holistic Earth geosystem approach in the curriculum are transmitted into the textbook, too. Besides these, more drawbacks are underlined in school textbook, which are:

1. The majority of the objectives are not adequately developed, owing to lack of explanatory text, pictures and maps.

2. Not only volcanoes and earthquakes as stated but also oceans and mountains are the surficial expressions of processes taking place in the Earth's interior.

3. Pictures, text and events seem to be organized incidentally. There is a lack of thinking and reasoning continuity, as well as lack of sequence of geologic events. As a result, processes and events are separately studied and not correlatively.

4. The omission of a reference to the geotectonic regime of Greece is a significant drawback, as Greece has been characterized as a 'living natural laboratory'.

5. The definition of the term "earthquake" is difficult for students. According to the textbook, earthquake is "... which is the instant result of a long-term procedure of accumulative potential energy which is enforced by the pressure of moving plates". Potential energy is only referred to as a type of energy and is not analyzed in depth in the primary school textbook. Therefore, the scientific information given is inconsistent with the age and cognitional student level, which means that the term earthquake has not been didactically transformed properly (scientific knowledge has been improperly "translated" into student knowledge). Thus, students cannot incorporate scientific information into their cognitional framework.

All the aforementioned drawbacks (from curriculum and textbook) lead to an inconsistency between students' cognition level and the scientific framework, and therefore conceptual change cannot be achieved. 


\section{The new geocause - PaP - CoRe approach and tha $\mathrm{GCl}$ tool}

It is obvious that geoscience curricula cannot depend only on age level, the obtained primary school knowledge framework and alternative ideas. New conceptual techniques and the Earth System Science literacy change the approach towards the geoscience curricula development. Therefore besides the transmission of single scientific terminology at school, it is necessary to re-focus on fundamentals.

We here propose a new approach in terms of Earth Science System, which considers Planet Earth as a continuously evolving dynamic Geosystem. Within these terms, we use specific keywords - basic axes which constitute the base the whole curriculum is built on. These keywords are developed in specific order so as to develop a logical sequence of events. This is because often students confuse facts of cause and facts of result, as for example, the notion that earthquakes are responsible for plate movements. So, this approach enables students to develop causal reasoning and geosystem thinking. The keywords we propose are: the Cause of the phenomenon, the Parameters affecting it, the accompanying Processes, their between Correlations and interactions and their Result, and finally the influence on environment that affects life. Our approach consisting of these fundamentals is called GeoCause - PaP - CoRe approach by the initials of the keywords.

This approach mainly focuses on a) Earth System, b) the cause of the phenomenon since causal reasoning facilitates and speeds conceptual change, c) the correlation among processes because it encourages thorough, criti- cal and system thinking. Because it is important that students capture an holistic image of Earth and do not see it as a rocky planet but as a ceaseless changing entity that beings are part of. Hence this approach constitutes the baseline for the construction of lithosphere curriculum and the teaching / learning procedures.

Educational procedures have to follow society trends and scientific evolution. But as they are based on the curricula, the latter must be enhanced continuously. Finally teaching and learning processes as well as curricula are dymanic and in no chance static, so they have to be continuously revised.

Libarkin and Anderson $(2005,2006)$ introduced the Geoscience Concept Inventory $(\mathrm{GCl})$ method. Its development and application on the study of learning in entry-level geoscience courses provides a common framework from which faculty can evaluate learning and teaching effectiveness at college level. The $\mathrm{GCl}$ is a set of conceptually based questions (pretest and posttest) geared towards foundational concepts in Earth Sciences. The GCl has also been proposed as a springboard for development of geoscience assessments for elementary students, and has been applied to assessment of high school students.

Based on the $\mathrm{GCl}$ method and the fact that curriculum is dynamic, we constructed a $\mathrm{GCl}$ questionnaire on lithosphere adjusted to junior high school standards, which is currently under pilot implementation. This $\mathrm{GCl}$ tool has been designed in order to continuously evaluate the progress of teaching and learning processes on lithosphere at school, and to use these results for the refinement of the lithosphere curriculum development constantly. 


\section{Suggested criteria on geoscience curriculla development}

Based on all the above and literature, we believe that school curriculum objectives on geosciences, as well as teaching and learning design, have to be revised and restructured. Below we list the criteria (existing, revised, new) we deem necessary for the reconstruction of geoscience curricula:

(1) the concept of Earth as a dynamic geosystem, which makes students to develop

$>$ geosystem thinking

$>$ scientific thinking based on causal reasoning

(2) the fact that students confuse the facts of cause with the facts of results (e.g. the plates move because of earthquake occurrence). This is one of the initiatives that the GeoCause - PaP CoRe method approach was applied

(3) the GeoCause - PaP - CoRe baseline approach (cause: Heat, parameters: temperature - pressure, processes: convective currents - plate motion, correlation: heat - convective currents - plate motion - geodynamic phenomena - Earth surface, result: earthquakes, volcanoes, mountains, oceans, surface formation, relief change)

(4) the fact that objectives must be solid and distinct

(5) the necessity for continuous revision of the curriculum through the $\mathbf{G C I}$ tool, which constantly resupplies the curriculum development

(6) age level

(7) obtained primary school knowledge framework

(8) alternative conceptions of students. Driver (1989) argues that these naove theories can either block or facilitate their learning of the scientific conceptions of natural processes. And this has serious ramifications for the construc- tion of the New Science Curriculum.

(9) Proper didactic transformation of scientific terminology, adjusted to school age level

(10) new teacher role and new student role

(11) new educational techniques and science evolution

(12) the fact that students are future citizenry and leaders to face huge environmental challenges

\section{Suggested lithosphere curriculum objectives}

According to the aforementioned criteria, the existing objectives on lithosphere for the 1st class Greek junior high school have been reconstructed and proposed as follows:

1. To describe and outline Earth structure from its interior to the surface (core - mantle - crust - lithosphere - tectonic plates and their correlation to oceans and continents)

2. To describe the parameters and conditions that affect the processes in the Earth's interior (temperature pressure)

3. To describe the geodynamic processes taking place from the interior to the surface of Earth (convective currents, plate motion, convergence, divergence, transcurrent movement)

4. To correlate the geodynamic processes with the parameters affecting them

5. To mention the initial cause of the processes (core heat)

6. To correlate the geodynamic processes with each other, thus the interior to the surface of Earth

7. To describe the manifestation of these geodynamic processes at the Earth's surface (result)

8. To describe earthquake occurrence, volcano, mountain and ocean forma- 
tion and their spatial distribution

9. To describe the constant change of the Earth's topography

10. To describe the continuously changing Earth interior and its relation to modification of the Earth's relief

11. To define the geotectonic regime of Greece

12. To realize that the Earth, and consequently the environment, is a giant and constantly evolving geosystem

13. To realize the influence of geodynamic phenomena on natural environment and to emphasize on the need for natural disaster management

14. Last, but not least, to make students responsible citizens, capable of making mature and effective decisions.

\section{Implementation of the suggested} lithosphere curriculum - conclusions For the evaluation of the effectiveness of the proposed lithosphere curriculum, a new experimental learning and teaching lesson plan on lithosphere has been designed, based on the aforementioned proposed criteria and curriculum objectives. The experimental lesson plan has placed emphasis on the GeoCause - PaP - CoRe baseline approach. A pilot implementation of the experimental lesson plan was applied on lithosphere unit of Geology - Geography at 1st grade of Greek junior high school. The pilot study was conducted according to the pretest and posttest methodology on an experimental group of about 40 subjects ( $47 \%$ boys, $53 \%$ girls) and a control group of about 40 subjects (55\% boys, $45 \%$ girls). The preliminary results are depicted in Table 1. The objectives of the experimental lesson were based on the main axes of GeoCause - PaP - CoRe baseline approach. Thus, the accomplishment of the objectives is depicted by the percentages of the main axes. The percentages reflect the right answers to each objective for each group and in each phase of the study.

The results of the above table can be interpreted as:

- The experimental group gives higher percentages after the lesson than the control group

- The objectives were successfully accomplished after the experimental lesson in the experimental group

- the existing lithosphere curriculum needs to be revised because it is static and not effective. It is obvious due to the low percentages after the lesson in the control group

\begin{tabular}{|l|c|c|c|c|}
\hline $\begin{array}{l}\text { Main axes of the } \\
\text { GeoCause - PaP - } \\
\text { CoRe }\end{array}$ & \multicolumn{2}{|c|}{ Control group } & \multicolumn{2}{c|}{ Experimental group } \\
\cline { 2 - 5 } & Pretest \% & Posttest \% & Pretest \% & Posttest \% \\
\hline $\begin{array}{l}\text { Geosystem - } \\
\text { Correlation }\end{array}$ & 0 & 1.2 & 0 & 35.9 \\
\hline Cause & 1.1 & 8 & 3.1 & 37.4 \\
\hline Parameters & 25.3 & 33.1 & 30.8 & 57.2 \\
\hline Processes & 5.7 & 7.1 & 6.2 & 25.4 \\
\hline Results & 1.1 & 9.7 & 7.7 & 33.8 \\
\hline
\end{tabular}

Table 1. Accomplishment of the objectives based on the main axes of the proposed GeoCause - PaP CoRe approach 
- the high percentages after the experimental lesson in the experimental group show that the GeoCause $\mathrm{PaP}$ - CoRe baseline approach led to the construction of an effective and geosystemically integrated lithosphere curriculum

- the GCl tool afforded us with qualitative and quantitative results

- the $\mathrm{GCl}$ tool contributed to the continuous feedback and revision of lithosphere curriculum objectives and learning process during the pilot study

- the suggested criteria contributed to the development of coherent and specific lithosphere curriculum objectives

- students managed to bridge the cognitional and conceptual gap and developed a concrete knowledge framework on lithosphere

- students conceived Earth as a continuously evolving dynamic system and not as cold rocky planet

- students' reference to earthquakes, volcanoes, mountains, oceans and Earth relief was made in conjunction with the evolving Earth's interior (correlation among processes, causal reasoning)

- students developed holistic geosystem reasoning and thinking.

\section{Suggestions}

Based on previous works on curriculum development and the pilot implementation of the proposed Greek lithosphere curriculum for Geology - Geography of 1st class junior high school, it is obvious that many existing geoscience curricula ignore Earth as a geosystem and lack approaches consisting of fundamentals such as thoroughness, cause, parameters, correlation and interaction, processes and result. Therefore, there is a lack of cognitional and conceptual continuity in the teaching and learning procedures. In order to bridge this gap and render geoscience curricula dynamic, we propose that:

- The GeoCause - PaP - CoRe approach can become the baseline for the (re-)construction of almost all geoscience curricula, teaching and learning processes

- The application of the $\mathrm{GCl}$ tool can become the source of continuous feedback and revision of all geoscience curricula and learning processes, with the proper adjustment to each particular topic

- The suggested criteria can be used to the development of geoscience curriculum in general.

\section{References}

Clark, S. K., Sibley, D. F., Libarkin, J. C. \& Heidemann, M., 2009. A novel approach to teaching and understanding transformations of matter in dynamic earth systems. Journal of Geoscience Education, 57(4), 233241.

Driver, R., 1989. Students' conceptions and the learning of science. International Journal of Science Education, 11(5), 481-490.

Eger, M., 1992. Hermeneutics and science education: An introduction. Science and Education, 1, 337-48.

Eger, M., 1993. Hermeneutics as an approach to science: Part II, Science and Education, 2, 303-28.

Frodeman, R., 1995. Geological reasoning: Geology as an interpretive and historical science. Geological Society of America Bulletin, 107, 960-968. Governmental Paper 2003. N. 1196 v. B'/26-8-2003 (in Greek).

Governmental Paper 2003. N. 304 v B'/ 13-3-2003 (in Greek). 
King, C., 2008. Geoscience education: an overview. Studies in Science Education, 44, 187-222.

Kuhn, D., Iordanou, K., Pease, M. \& Wirkala, C. (2008) Beyond control of variables: What needs to develop to achieve skilled scientific thinking? Cognitive Development, 23(4), 435451.

Leontakianakos, G., Vrachas, C., Baziotis, G., Baziotis, I., Soultati, G. and Fermeli, G., 2013. Theoretical approach of teaching lithosphere in junior high school. A critical review of the content and objectives defined by the curriculum of the ministry of education. Bulletin of the Geological Society of Greece, vol. XLVII, Proceedings of the 13th International Congress, Chania, Sept. 2013.

Libarkin, J. \& Anderson, S., 2005. Assessment of learning in Entry-Level Geosciences Courses: Results from the Geoscience Concept Inventory. Journal of Geoscience Education, v. 53 (4), 394-401.
Libarkin, J. C., Anderson, S. W., Deeds, D. \& Callen, B., 2006. Development of the geoscience concept inventory. Proceedings of the National STEM Assessment Conference, Washington DC.

Mayer \& Kumano, 1999. The Role of System Science in Future School Science Curricula. Studies in Science Education, 34 (1), 71-91.

Mayer 1993. The future of the Geosciences in the Pre-College Curriculum.

Merritts D., D. W. A., Menking K., 1998. Environmental geology, an earth system science approach. 452.

Pavlopoulos, K. \& Galani, A., 2009. Geology \& Geography Textbook, A' Class of High School, Athens, OEDB, $175 \mathrm{pp}$ (in Greek).

Senge, P., 1990. The fifth discipline: The art and practice of the learning organization. New York: Doubleday Currency. 